\title{
A paradigm mix or shift? an analysis of the uk fetal anomaly screening programme
}

\section{Opinion}

According to WHO, wellbeing is a state in which the individual realizes his/her potential, can cope with normal stresses of life, can work productively and fruitfully, and is able to make a contribution to his/her community. ${ }^{1,2}$ However, behind this official definition of wellbeing there are different ways of talking about wellbeing, with different concepts of and different ideas concerning the way in which wellbeing can be realized. We call these ways of talking about wellbeing for "discourses of wellbeing", and we will briefly present two dominant discourses: the public health discourse of wellbeing and the learning oriented discourse of wellbeing. While the former focuses on risk aspects, prevention and on behaviorally oriented interventions, the latter focuses on learning and on pedagogical interventions. We will elaborate on these two discourses by referring to

\section{i. A Danish National Report of wellbeing of adolescents. ${ }^{1}$}

ii. Students wellbeing linked to their participation in the Danish school gardens program 'Gardens for Bellies'. ${ }^{3,4}$

According to the public health discourse, wellbeing can be characterized by being mentally healthy. In order to achieve a state of wellbeing, the individual must avoid to be mentally threatened, e.g. being lonely, feeling anxiety, suffering from low self-esteem, being self-destructive or having a mental diagnosis, for example ADHD, depression or other diagnoses that demand medical treatment. Wellbeing is analyzed and expressed through the concept of "risk behaviour". The public health discourse of wellbeing is a subset of the general health paradigm, and consequently the dominating concepts are concepts like "disease", "risk", "treatment" and sociomedical interventions. Lack of wellbeing is seen as the result of social infection, and consequently e.g. young people suffering from the lack of wellbeing should be treated medically or through social interventions. Consequently, a high level of wellbeing is characterized by a risk-free or non-disease state of affairs. A prominent example of this discourse of wellbeing can be found in the above mentioned Danish National Report of wellbeing of adolescents. Looking at the questionnaire behind the report, most questions are characterized by negative values: "Are you too busy?" "Do you feel lonely?" "Have you tried to harm yourself?" "Have you ever tried to commit suicide?"etc. It is obvious, that wellbeing is characterized negatively: Feeling well is avoiding the risks of factors that harm wellbeing. The means to realize wellbeing are medically informed and focus on changing individuals through medical or social interventions. The idea behind this discourse is that wellbeing can be realized through causally based interventions, i.e. that the individual human being is open to external interventions. One of the representatives of this discourse, Professor Carsten Obel, head of Center for Health Collaboration, Aarhus University, Denmark, has used the metaphor that we have to invent a "pill" for the provision of wellbeing.

According to the learning oriented discourse, wellbeing is characterized positively, i.e. as an expression of happiness that renders feelings of energy, courage, vigor and joy of being together with others. ${ }^{3}$ In this discourse, wellbeing is a general concept that
Volume 6 Issue 2 - 2017

Karen Wistoft, Lars Qvortrup
Department of Education, Aarhus University, Denmark

Correspondence: Karen Wistoft, Department of Education, Aarhus University, Denmark, Tel +45 8716 3823, Email kawi@edu.au.dk

Received: August 10,2017| Published: August 15, 2017

expresses a subjective experience of a person's own situation as well as the assessment of his/her surroundings, e.g. friends, parents or teachers. In recent children health education research, the wellbeing concept is used as a characteristic of a child's own assessment of

i. Its social affiliations including its relationship with peers and its network.

ii. Whether it has someone to confide in.

iii. Being surrounded by responsible adults who exercise care, keep agreements and do not fail them

iv. Is in a setting, where it is pleasant to be. ${ }^{3}$

While the public health discourse of wellbeing is a subset of the general health paradigm, the learning discourse of wellbeing is a subset of the general educational and sociological paradigm. The idea behind this discourse is that wellbeing must be realized by the individuals themselves through learning processes. Learning cannot be "injected" by external actors. On the contrary, learning is an internal mental process that can only be supported from "the outside". This implies that external factors can only change the wellbeing of the individual indirectly, e.g. by establishing a supportive environment and by supporting learning processes that lead towards wellbeing of the individual and of communities of individuals.

This discourse can be illustrated by examples from the Danish "Gardens for Bellies" school garden program. The school garden program normally consists of eight class visits to centrally located gardens or to gardens located in or close to a school. The ages of students attending the gardens range from Kindergarten to $9^{\text {th }}$ grade. Being outside in nature and learning in the school garden program contributes to student's sense of wellbeing and their social relations. This is for instance promoted by helping students realize their own potential through gaining successful experiences of working productively with growing their own food, cooking homegrown vegetables, having courage to try new challenging experiences (e.g. tasting new plants and insects, touching animal manure) and of being able to make a contribution to his/her group, the garden and home. 
Many expressed a deep experience of happiness and joy from learning in nature, being together with each other and learning from inspiring garden educators. The student's wellbeing in the gardens appears to be associated with being outside in nature and with participating in social interactions in the gardens, with peers, garden educators, and teachers giving them opportunity to actively participate in garden activities. The findings acknowledge how the social environment and roles are friendly and encourage cooperation in the gardens, but also that the natural environment has a special impact on the student's self-reported sense of wellbeing. As a result the majority of students thought back on their garden experience with great excitement two months after completing it. Several said: "It's the best school year of my entire life" and expressed how it impacted their mood and happiness.

Summing up the Program "Gardens for Bellies" represents the learning oriented discourse of wellbeing. Wellbeing is defined in positive terms, it is seen as the result of learning processes, and wellbeing can be achieved only indirectly by external actors who can create a positive social environment and can provide learning opportunities, thus supporting the individual's own mental learning processes. In conclusion, the two discourses concerning wellbeing can be summarized in the following scheme (Table 1).
Table I

\begin{tabular}{lll}
\hline $\begin{array}{l}\text { Definition of } \\
\text { wellbeing }\end{array}$ & Provision of wellbeing & \\
\hline $\begin{array}{l}\text { The public health } \\
\text { discourse }\end{array}$ & $\begin{array}{l}\text { A risk-free or non-disease } \\
\text { state of affairs }\end{array}$ & $\begin{array}{l}\text { Through } \\
\text { behaviorally } \\
\text { oriented, causal } \\
\text { interventions }\end{array}$ \\
& $\begin{array}{l}\text { Through indirect } \\
\text { interventions, e.g. } \\
\text { by establishing } \\
\text { a supportive } \\
\text { environment and } \\
\text { be learning } \\
\text { oriented } \\
\text { discourse }\end{array}$ & $\begin{array}{l}\text { An expression of happiness } \\
\text { that renders feelings of } \\
\text { energy, courage, vigor and joing oriented } \\
\text { of being together with others } \\
\text { learning processes }\end{array}$ \\
\hline
\end{tabular}

\section{Acknowledgements}

None.

\section{Conflict of interest}

Author declares that there is no conflict of interest. 